\title{
Safety of Aflibercept in Metastatic Colorectal Cancer: A Literature Review and Expert Perspective on Clinical and Real-World Data
}

\author{
Kei Muro ${ }^{1, * \mathbb{D}}$, Taylor Salinardi ${ }^{2}$, Arvind Rup Singh ${ }^{2}$ and Teresa Macarulla ${ }^{3}$ \\ 1 Department of Clinical Oncology, Aichi Cancer Center Hospital, Nagoya 464-8681, Japan \\ 2 Global Medical Oncology, Sanofi, Boston, MA 02142, USA; Taylor.Salinardi@sanofi.com (T.S.); \\ Arvind.Singh@sanofi.com (A.R.S.) \\ 3 Gastrointestinal Tumors Service of the Medical Oncology Service, Vall d'Hebron University Hospital, \\ Vall d'Hebron Institute of Oncology, IOB, Barcelona 08035, Spain; tmacarulla@vhio.net \\ * Correspondence: kmuro@aichi-cc.jp; Tel.: +81-52-762-6111 (ext. 3777); Fax: +81-52-764-9855
}

Received: 25 February 2020; Accepted: 27 March 2020; Published: 31 March 2020

check for updates

\begin{abstract}
Background: Metastatic colorectal cancer (mCRC) represents a substantial health burden globally and an increasing challenge in Asian countries. Treatment options include chemotherapy plus a vascular endothelial growth factor (VEGF) inhibitor (such as bevacizumab, aflibercept or ramucirumab), or anti-epidermal growth factor receptor (EGFR) therapies. Aflibercept, a recombinant fusion protein, has been approved for treatment of mCRC in combination with FOLFIRI for patients whose disease progresses during or after treatment with an oxaliplatin-containing regimen, based on its efficacy and tolerability profile in clinical trials. This report aims to provide an overview of both clinical and real-world evidence and experience on the use of aflibercept in routine clinical practice, with a focus on European, American and Asian populations. Methods: A literature search was conducted in PubMed (on 28th February 2019) using the search terms ("aflibercept") and ("Colorectal"OR"CRC") to identify publications containing information on aflibercept-containing regimens. Results: The adverse events (AE) profile was similar between geographical locations. Across trials, real-world and retrospective studies, grade $\geq 3$ hypertension and proteinuria were amongst the most frequently reported AEs. Conclusions: The safety profile of aflibercept is generally manageable and comparable across various geographic locations.
\end{abstract}

Keywords: colorectal cancer; mCRC; VEGF inhibitor; anti-angiogenic therapy; aflibercept; clinical practice

\section{Introduction}

The global burden of colorectal cancer (CRC) is expected to increase by $60 \%$ to more than 2.2 million new cases and 1.1 million deaths by 2030. It is the second most frequently diagnosed cancer and the fourth leading cause of cancer-related death worldwide [1,2]). In Europe, 2018 estimates indicate that $\mathrm{CRC}$ is the second most frequently occurring cancer and cause of death from cancer [3]. Increases in incidence and mortality have been seen in Eastern Europe, where as other European countries have exhibited an increase in incidence but a decline in mortality [1]. In Asia, CRC rates are increasing rapidly, and it is now the third most frequently occurring malignancy in both men and women. Mortality from CRC has been increasing in Asian countries over the last decade, with the exception of Japan and Singapore [1,4]. According to the vital statistics of Japan in 2015, CRC was the most frequent cause of cancer deaths in women [5]. A multinational cohort study involving four Asian countries (Taiwan, Korea, Japan, and Hong Kong) demonstrated that the incidence of young-onset CRC has 
significantly increased in both men and women in the past two decades [6]. Although CRC occurrence is similar in Europe and Asia, the treatment strategies are different.

This paper aims to evaluate current safety data reported for aflibercept in mCRC using clinical and real-world/retrospective data. After reviewing these data, insights on patient management from different perspectives will be provided in order to help inform treatment decisions in this disease setting.

\section{Methods}

A literature search was conducted in PubMed using the search terms ("aflibercept") and ("colorectal"OR"CRC") to identify publications available cumulatively until March 13, 2020 containing information on aflibercept-containing regimens. Identified publications were reviewed and those including safety data were selected. Both clinical trials and real-world data (including observational and retrospective studies) were included. Review articles and reports with a focus on efficacy were excluded from the analysis. In order to obtain studies reporting safety data from a sufficient number of patients, individual case reports/case series with $<5$ patients were also excluded. Google Scholar was used to access an article known to have only been presented at a congress (Figure 1).

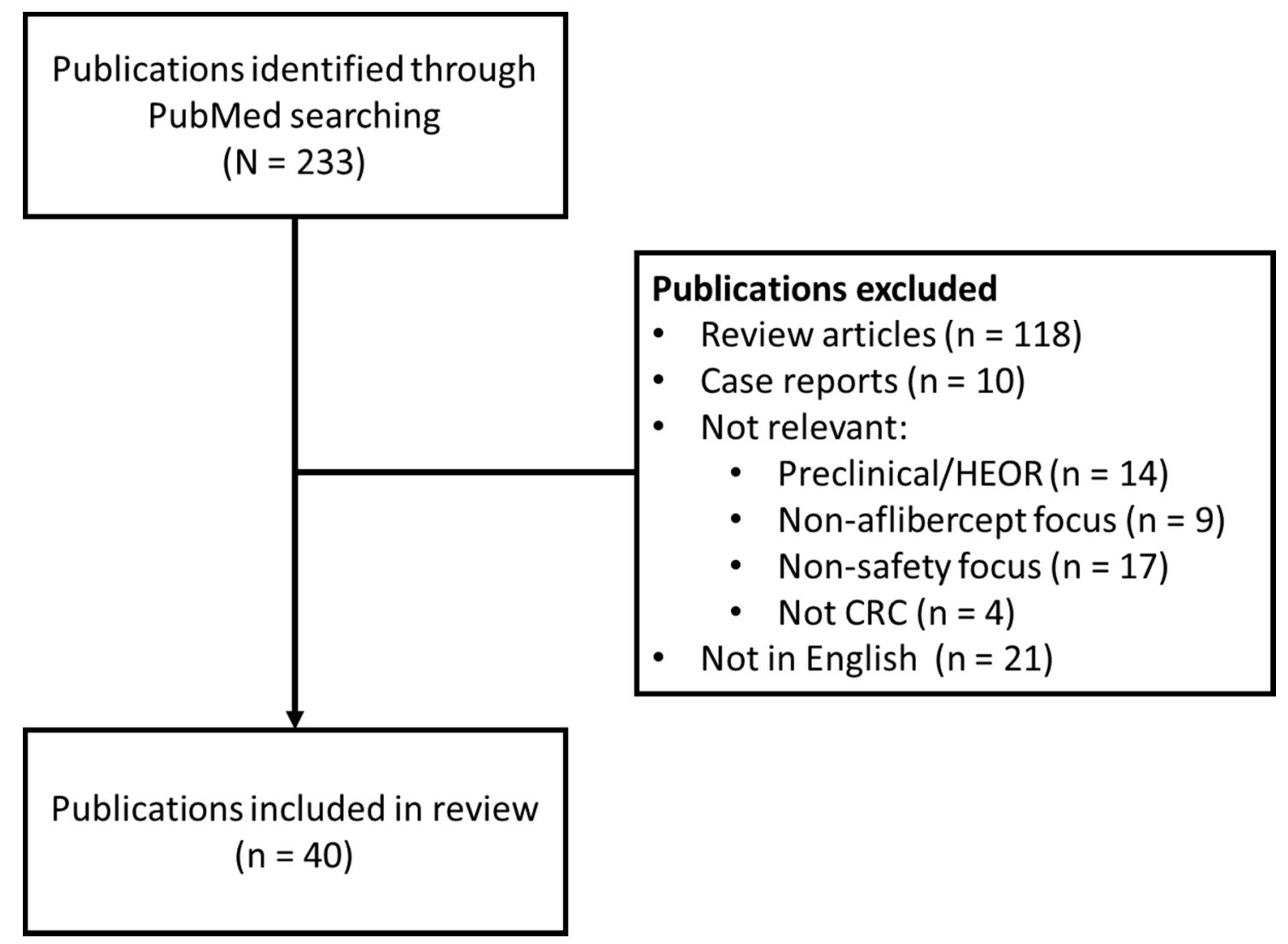

Figure 1. PRISMA flow diagram: summary of literature search outcomes.

\section{Results}

\section{Aflibercept Mechanism of Action and Relevance To Safety Profile}

Aflibercept is a recombinant fusion protein composed of the second immunoglobulin (Ig)-like domain of FLT1 (VEGFR1) joined to the third Ig-like domain of KDR (VEGFR2) fused to the Fc portion of human IgG1 (Figure 2). Aflibercept differs from other anti-VEGF agents by functioning as a decoy receptor with high-affinity for other angiogenic factors, VEGF-B and placental growth factor (PlGF). Additionally, PIGF has been proposed as a mechanism of bevacizumab resistance. 
Consequently, aflibercept's binding affinity for PIGF has been hypothesized to contribute to its efficacy in the post-bevacizumab setting [7].

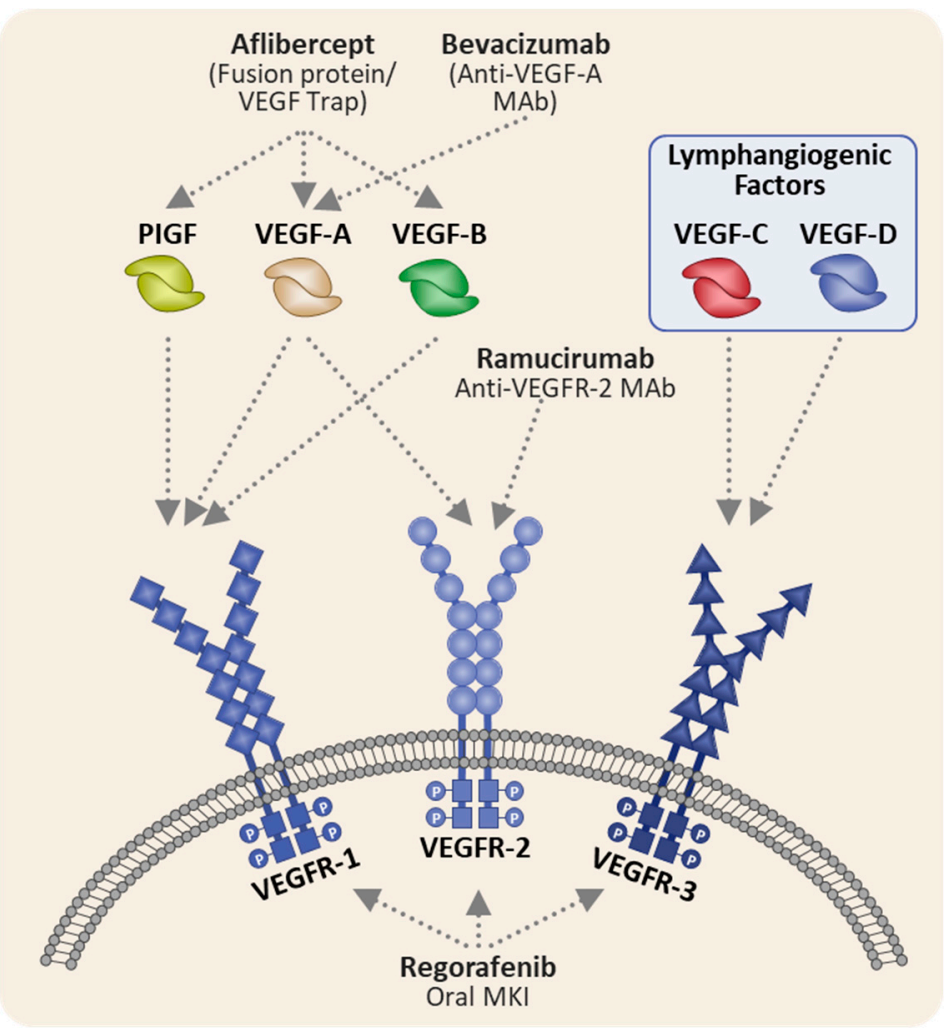

Figure 2. Mechanism of action of anti-VEGF agents in colorectal cancer (adapted from Clarke et al. [8]). $\mathrm{mAB}$, monoclonal antibody; MKI, multikinase inhibitor; PIGF, placental growth factor; VEGF, vascular endothelial growth factor; VEGF-R, vascular endothelial growth factor receptor. VEGFR-1 is transcribed from the Fms-related receptor tyrosine kinase (FLT1) gene, VEGFR-2 from the Kinase Insert Domain Receptor (KDR) and VEGFR-3 from the FLT3 gene.

Tumors exploit angiogenic pathways to facilitate rapid and uncontrolled proliferation. Using anti-angiogenics inhibits the formation of new vessels within the tumor and leads to hypoxia and tumor death. Although angiogenesis occurs at a lower rate in adults, these pathways are used for vascular homeostasis. For example, VEGF promotes the release of nitric oxide, a vasodilator, which may explain why anti-angiogenics are frequently associated with hypertension. Proteinuria, another frequent adverse event (AE) associated with anti-angiogenics, may be due to VEGF reductions leading to decreased nephrin expression, subsequently resulting in podocyte dysfunction. Anti-angiogenics are also associated with non-cardiovascular AEs, due to the complexity of the VEGF signaling pathway $[9,10]$.

\section{Safety Profile of Aflibercept-Containing Therapy in mCRC}

\subsection{Aflibercept and FOLFOX/FOLFIRI in Clinical Trials}

\subsubsection{Global Studies}

The safety and efficacy of aflibercept has been evaluated in several global clinical trials (Figure 3). VELOUR was an international randomized, placebo-controlled Phase III trial comparing the efficacy and safety of aflibercept plus FOLFIRI $(n=612)$ and placebo plus FOLFIRI $(n=614)$ in patients with $\mathrm{mCRC}$ who had previously received oxaliplatin based chemotherapy. Addition of aflibercept to FOLFIRI significantly improved efficacy outcomes compared with placebo plus FOLFIRI. 


\begin{tabular}{|c|c|c|c|c|c|c|c|c|c|c|c|}
\hline \multirow[b]{3}{*}{ Adverse event } & \multicolumn{11}{|c|}{ Clinical trials } \\
\hline & \multicolumn{2}{|c|}{ Global } & \multicolumn{5}{|c|}{ Europe / US/Canada } & \multicolumn{4}{|c|}{ Asia } \\
\hline & 1 & 2 & 3 & 4 & 5 & 6 & 7 & 8 & 9 & 10 & 11 \\
\hline \multicolumn{12}{|l|}{ Hematologic } \\
\hline \multicolumn{12}{|l|}{ Neutropenia } \\
\hline \multicolumn{12}{|l|}{ Febrile neutropenia } \\
\hline \multicolumn{12}{|l|}{ Leukopenia } \\
\hline \multicolumn{12}{|l|}{ Non-hematologic } \\
\hline \multicolumn{12}{|l|}{ Hypertension } \\
\hline \multicolumn{12}{|l|}{ Proteinuria } \\
\hline Diarrhea & O & O & & O & & & O & O & C & O & \\
\hline \multicolumn{12}{|l|}{ Mucositis } \\
\hline \multicolumn{12}{|l|}{ Abdominal pain } \\
\hline \multicolumn{12}{|l|}{ Peripheral neuropathy } \\
\hline \multicolumn{12}{|l|}{ Asthenia/fatigue } \\
\hline \multicolumn{12}{|l|}{ Stomatitis ( \pm ulceration) } \\
\hline \multicolumn{12}{|l|}{ Infections / infestations } \\
\hline \multicolumn{12}{|c|}{ Decreased appetite / weight loss / anorexia } \\
\hline Venous thromboembolism & & & & & & & 0 & & & & \\
\hline
\end{tabular}

This table is provided for ease of viewing information from multiple trials. Direct comparison between trials is not intended and should not be inferred. Patient populations and study designs differ 1. Folprecht 2016; 2. van Cutsem 2012; 3. Chibaudel 2019; 4. Pentheroudakis 2018; 5. Tang 2012; 6. Matikas 2019; 7. Lapeyre-Prost 2018; 8. Li 2018; 9. Denda 2019; 10. Xu 2017; 11. Yoshino 2013.

Key: Adverse events Grade $\geq 3$

$10-15 \%$

$>15-20 \%$

$>20-25 \%$

$>25-30 \%$

$>30-35 \%$

$>35-40 \%$

Figure 3. Summary of Grade $\geq 3$ adverse events occurring in $\geq 10 \%$ of patients across clinical trials of aflibercept in patients with mCRC. 
The experimental arm demonstrated a statistically significant benefit in overall survival (OS; median 13.50 months versus 12.06 months; $p=0.0032$ ), progression-free survival (PFS; median 6.90 months versus 4.67 months; $p<0.0001)$, and response rates $(19.8 \%$ versus $11.1 \% ; p=0.0001)$ compared with the control arm. The most frequently occurring Grade $\geq 3$ AEs in patients who received aflibercept plus FOLFIRI were neutropenia (laboratory measurements: $36.7 \%$, versus $29.5 \%$ for placebo plus FOLFIRI), hypertension (19.3\%, versus $1.5 \%$ for placebo plus FOLFIRI), diarrhea (19.3\%, versus $7.8 \%$ for placebo plus FOLFIRI), asthenia (16.8\%, versus $10.6 \%$ for placebo plus FOLFIRI), stomatitis and ulceration $(13.8 \%$, versus $5.0 \%$ for placebo plus FOLFIRI) and infections and infestations (12.3\%, versus $6.9 \%$ for placebo plus FOLFIRI). AEs observed at $\geq 5 \%$ in either arm are summarized in Table 1. Rates of any grade arterial thrombotic events were $1.5 \%$ for placebo plus FOLFIRI (0.5\% grade 3$)$ and $2.6 \%$ for aflibercept plus FOLFIRI $(0.8 \%$ grade 3 and $1.0 \%$ grade 4$)$ [11]. In a post hoc analysis, the incidence of grade $3 / 4$ AEs was higher for patients $\geq 65$ years of age than for those $<65$ years of age in both the aflibercept $(89.3 \%$ vs $80.5 \%)$ and placebo $(67.4 \%$ vs $59.4 \%)$ arms. Interaction tests for grade $3 / 4$ antiangiogenic agent-related AEs suggested no heterogeneity between the older and younger patient populations $(p>0.1)$ [12]. Similarly, another post hoc analysis did not identify any differences in all grade and grade 3/4 AEs between the subgroup of patients with better and poorer efficacy [13]. Importantly, the majority of grade 3/4 AEs occurred within 4 cycles of treatment, in a small percent of treatment cycles, and were mostly reversible [14].

The Aflibercept Safety and Quality-of-Life Program (ASQoP) was an open-label single-arm trial evaluating the effect of second-line aflibercept plus FOLFIRI on the quality of life and safety of patients with $\mathrm{mCRC}$ in a real-world setting (in a similar patient population as the VELOUR study). An interim analysis based on 779 patients demonstrated that aflibercept-related AEs were similar in ASQoP and VELOUR, though the frequency of some AEs appeared lower in ASQoP, which may reflect more flexible $n$ FOLFIRI dosing, or more experience in AE management (Table 2; $[15,16])$.

The AFFIRM study compared aflibercept in combination with modified FOLFOX6 (mFOLFOX6; $n=119)$ with mFOLFOX6 alone $(n=117)$ for the first-line treatment of mCRC (Figure 3$)$. Rates of AEs were generally increased in the aflibercept arm compared with mFOLFOX6 alone, and the most frequently occurring grade $\geq 3$ AEs were neutropenia (36.1\% vs $29.3 \%$ ), hypertension ( $35.3 \%$ vs $1.7 \%$ ), peripheral sensory neuropathy (16.8\% vs $17.2 \%)$, and diarrhea (13.4\% vs $5.2 \%)$. One patient died as a result of an intracranial hemorrhage (unrelated to aflibercept) and four others from infections (also determined not related to study treatment) [17]. In a separate analysis of the AFFIRM study data, no association was found between certain biomarkers (somatic mutations in oncogenic drivers of mCRC, common single-nucleotide polymorphisms in VEGF pathway genes and plasma markers) and AEs [18]. 
Table 1. Summary of adverse events (any grade) $\geq 5 \%$ in the VELOUR trial of placebo plus FOLFIRI vs aflibercept plus FOLFIRI [11].

\begin{tabular}{|c|c|c|c|c|c|c|}
\hline \multirow{2}{*}{ Adverse Event } & \multicolumn{3}{|c|}{ Placebo Plus FOLFIRI $(n=605)$} & \multicolumn{3}{|c|}{ Aflibercept Plus FOLFIRI $(n=611)$} \\
\hline & All grades $(\%) *$ & Grade $3(\%) *$ & Grade $4(\%) *$ & All Grades (\%) * & Grade $3(\%) *$ & Grade $4(\%) *$ \\
\hline Any & 97.9 & 45.1 & 17.4 & 99.2 & 62.0 & 21.4 \\
\hline Diarrhea & 56.5 & 7.6 & 0.2 & 69.2 & 19.0 & 0.3 \\
\hline Asthenic conditions & 50.2 & 10.4 & 0.2 & 60.4 & 16.0 & 0.8 \\
\hline Stomatitis and ulceration & 34.9 & 5.0 & - & 54.8 & 13.6 & 0.2 \\
\hline Nausea & 54 & 3.0 & - & 53.4 & 1.8 & - \\
\hline Infections and infestations & 32.7 & 6.1 & 0.8 & 46.2 & 11.0 & 1.3 \\
\hline Hypertension & 10.7 & 1.5 & - & 41.4 & 19.1 & 0.2 \\
\hline Hemorrhage & 19 & 1.7 & - & 37.8 & 2.8 & 0.2 \\
\hline Epistaxis & 7.4 & - & - & 27.7 & 0.2 & - \\
\hline GI and abdominal pains & 29.1 & 3.1 & 0.2 & 34 & 5.1 & 0.3 \\
\hline Vomiting & 33.4 & 3.5 & - & 32.9 & 2.6 & 0.2 \\
\hline Decreased appetite & 23.8 & 1.7 & 0.2 & 31.9 & 3.4 & - \\
\hline Weight decreased & 14.4 & 0.8 & - & 31.9 & 2.6 & - \\
\hline Alopecia & 30.1 & - & - & 26.8 & - & - \\
\hline Dysphonia & 3.3 & - & - & 25.4 & 0.5 & - \\
\hline Constipation & 24.6 & 1.0 & - & 22.4 & 0.8 & - \\
\hline Headache & 8.8 & 0.3 & - & 22.3 & 1.6 & - \\
\hline PPES & 4.3 & 0.5 & - & 11.0 & 2.8 & - \\
\hline VTE & 7.3 & 2.6 & 3.6 & 9.3 & 3.1 & 4.7 \\
\hline Anemia & 91.1 & 3.5 & 0.8 & 82.3 & 3.3 & 0.5 \\
\hline Neutropenia & 56.3 & 19.1 & 10.4 & 67.8 & 23.1 & 13.6 \\
\hline Thrombocytopenia & 33.8 & 0.8 & 0.8 & 47.4 & 1.7 & 1.7 \\
\hline Proteinuria & 40.7 & 1.2 & - & 62.2 & 7.5 & 0.3 \\
\hline ALT increased & 37.1 & 2.2 & - & 47.3 & 2.5 & 0.2 \\
\hline
\end{tabular}

ALT, alanine aminotransferase; GI, gastrointestinal; PPES, palmar-plantar erythrodysesthesia syndrome; VTE, venous thromboembolic event. * Grades were determined according to National Cancer Institute Common Terminology Criteria of Adverse Events, version 3.0. 
Table 2. Safety data from the fifth interim analysis of ASQoP compared with VELOUR $[15,16]$.

\begin{tabular}{|c|c|c|c|c|c|c|}
\hline \multirow{2}{*}{ Adverse Events } & \multicolumn{3}{|c|}{$\begin{array}{c}\text { ASQoP } \\
\text { Aflibercept + FOLFIRI }(n=779)\end{array}$} & \multicolumn{3}{|c|}{$\begin{array}{c}\text { VELOUR } \\
\text { Aflibercept }+ \text { FOLFIRI }(n=611)\end{array}$} \\
\hline & All Grades (\%) [15] & Grade 3-4 (\%) [15] & Grade $4(\%)$ [16] & All grades (\%) & Grade 3-4 (\%) & Grade $4(\%)$ \\
\hline Any treatment-emergent adverse event & 98.7 & 78.2 & 18.0 & 99.2 & 83.5 & 21.4 \\
\hline \multicolumn{7}{|c|}{ Selected treatment-emergent adverse events of any grade in $\geq 20 \%$ of patients } \\
\hline Diarrhea & 61.6 & 15.3 & 0.3 & 69.2 & 19.3 & 0.3 \\
\hline Asthenic conditions & 57.8 & 13.6 & 0 & 60.4 & 16.9 & 0.8 \\
\hline Hypertension & 48.4 & 24.1 & 0 & 41.4 & 19.3 & 0.2 \\
\hline Stomatitis $^{1}$ (and ulcerations) ${ }^{2}$ & 42.9 & 10.5 & 0.1 & 54.8 & 13.7 & 0.2 \\
\hline Infections and infestations $^{2}$ & 31.3 & 11.7 & 2.1 & 46.2 & 12.3 & 1.3 \\
\hline Venous thromboembolic events ${ }^{2}$ & 6.2 & 4.1 & 0.9 & 9.3 & 7.9 & 4.7 \\
\hline Arterial thromboembolic events ${ }^{2}$ & 2.3 & 0.8 & 0.3 & 2.6 & 1.8 & 1.0 \\
\hline Neutropenia & $60.5^{*}$ & $30.5^{*}$ & $9.7^{*}$ & $67.8^{* *}$ & $36.7^{* *}$ & $13.6^{* *}$ \\
\hline Proteinuria & 60.1 & 7.6 & 0.6 & 62.2 & 7.9 & 0.3 \\
\hline
\end{tabular}




\subsubsection{European and US Studies}

First-line aflibercept was evaluated in two European studies. In a French study, 49 patients with previously untreated $\mathrm{mCRC}$ received aflibercept plus FOLFOX followed by maintenance therapy with fluoropyrimidine (Figure 3). The most frequently occurring grade 3/4 AEs were hypertension (23\%), fatigue $(15 \%)$, neutropenia (laboratory measurement: $12 \%)$, neuropathy $(12 \%)$ and stomatitis (10\%). There were three $(6 \%)$ treatment-related deaths due to stroke, pulmonary embolism and neutropenic sepsis [19]. In a study by the Hellenic Cooperative Oncology Group, first-line aflibercept plus FOLFIRI was evaluated in 73 patients with $\mathrm{mCRC}$ (Figure 3). The most frequently occurring grade $3 / 4$ AEs were hypertension (26\%), neutropenia (18\%), diarrhea (15\%), proteinuria (11\%) and infections (11\%). No deaths due to AEs were reported [20].

A Phase II study evaluated first-line FOLFIRI/aflibercept in Greek patients $(\mathrm{N}=31)$ with mCRC. There was one toxic death due to sepsis. Grade 3/4 AEs included neutropenia (16.1\%), diarrhea (19.4\%), hypertension (12.9\%), asthenia (9.7\%), proteinuria (3.2\%) and bowel perforation (3.2\%) [21].

A Phase II single-arm multicentric study analyzed 40 patients with mCRC across nine French centers who were treated with first-line FOLFIRI. Grade 3/4 AEs were mainly gastrointestinal (45\%: mucositis (15\%), diarrhea (12.5\%), abdominal pain $(10 \%)$ and vascular $(32.5 \%$ : hypertension $(17.5 \%)$ and venous thromboembolism [15\%]). Severe hematological toxicities occurred in $7.5 \%$ of patients. $87.5 \%$ of patients had at least one dose modification during treatment [22].

A Phase II study evaluated aflibercept in patients with $\mathrm{mCRC}$, in Canada and the US, who had received prior bevacizumab $(n=51)$ or who were bevacizumab-naïve $(n=24)$ (Figure 3$)$. The most frequently occurring grade $3 / 4$ AEs were hypertension (13.5\%) and proteinuria (10.8\%). Ten patients discontinued aflibercept due to AEs, including five patients for severe hypertension and proteinuria [23].

\subsubsection{Asian Studies}

Several clinical trials evaluating second-line aflibercept have been undertaken across Asia. A Phase III study of aflibercept plus FOLFIRI in Asian patients with pre-treated mCRC included 111 evaluable patients (Figure 3). The most frequently occurring grade $\geq 3$ AEs were neutropenia (29\%), hypertension $(18 \%)$, diarrhea $(17 \%)$ and stomatitis $(11 \%)$. There were two treatment-related deaths in this patient group, four in the aflibercept plus FOLFIRI group and one in the placebo plus FOLFIRI only group [24].

In a Japan-specific study, 62 patients with mCRC were evaluated following second-line aflibercept plus FOLFIRI. The most frequently occurring grade 3/4 AEs were neutropenia (61.3\%), hypertension $(27.4 \%)$, diarrhea (19.4\%) and decreased appetite (12.9\%). There were no treatment-related deaths [25]. In a separate Japanese study, evaluating aflibercept $(2 \mathrm{mg} / \mathrm{kg}$ or $4 \mathrm{mg} / \mathrm{kg}$ ) plus FOLFIRI in 14 patients with previously treated $\mathrm{mCRC}$, the most frequently occurring grade $3 / 4$ AEs were neutropenia $(76.9 \%)$, leukopenia (61.5\%), hypertension (30.8\%) and stomatitis (15.4\%) [26].

A Phase I study has investigated aflibercept plus FOLFIRI in Chinese patients with metastatic solid malignancies $(\mathrm{N}=20)$. In patients with $\mathrm{mCRC}(\mathrm{N}=15)$, the most common grade $\geq 3$ AEs were neutropenia (35\%), hypertension (30\%), stomatitis (20\%), proteinuria (20\%), leukopenia (15\%), febrile neutropenia $(15 \%)$ and diarrhea $(15 \%)$. There were no deaths during the study period [27].

Aflibercept had a consistent safety profile across clinical studies and regions. The most frequent AEs included neutropenia, hypertension and gastrointestinal issues.

\subsection{Aflibercept and FOLFOX/FOLFIRI in Real-World and Retrospective Studies}

\subsubsection{European and the US Studies}

Several retrospective studies have evaluated the real-world safety implication of aflibercept plus chemotherapy. In general, grade $\geq 3$ AEs occurred at a lower rate compared with the rates observed in clinical trials (Figure 4). 


\begin{tabular}{|c|c|c|c|c|c|c|c|c|c|c|c|c|c|c|c|}
\hline \multirow[b]{3}{*}{ Adverse event } & \multicolumn{15}{|c|}{ Real-world / retrospective studies } \\
\hline & \multicolumn{13}{|c|}{ Europe / US } & \multicolumn{2}{|c|}{ Asia } \\
\hline & 1 & 2 & 3 & 4 & 5 & 6 & 7 & 8 & 9 & 10 & 11 & 12 & 13 & 14 & 15 \\
\hline \multicolumn{16}{|l|}{ Hematologic } \\
\hline \multicolumn{16}{|l|}{ Neutropenia } \\
\hline \multicolumn{16}{|l|}{ Febrile neutropenia } \\
\hline \multicolumn{16}{|c|}{ Neutropenic complications } \\
\hline \multicolumn{16}{|l|}{ Leukopenia } \\
\hline \multicolumn{16}{|l|}{ Anemia } \\
\hline \multicolumn{16}{|l|}{ Non-hematologic } \\
\hline \multicolumn{16}{|l|}{ Hypertension } \\
\hline \multicolumn{16}{|l|}{ Proteinuria } \\
\hline \multicolumn{16}{|l|}{ Diarrhea } \\
\hline \multicolumn{16}{|l|}{ Bowel obstruction } \\
\hline \multicolumn{16}{|l|}{ Neuropathy } \\
\hline \multicolumn{16}{|l|}{ Asthenia/fatigue } \\
\hline \multicolumn{16}{|l|}{ Stomatitis ( \pm ulceration) } \\
\hline \multicolumn{16}{|l|}{ Infections / infestations } \\
\hline \multicolumn{16}{|c|}{ Decreased appetite / weight loss / anorexia } \\
\hline Liver enzyme elevation & & & & & & & & & & & & & & & \\
\hline
\end{tabular}

This table is provided for ease of viewing information from multiple trials. Direct comparison between trials is not intended and should not be inferred. Patient populations and study designs differ.

1. Fernández Montes 2019 (Cancer Medicine); 2. Giuliani, Bonetti 2016; 3. Carola 2018; 4. Pastorino 2018; 5. Ivanova 2017; 6. Felui 2017; 7. Fernández Montes 2017; 8. González-Flores 2017; 9. Martínez-

Lago 2019; 10. Fernández Montes 2019 (Oncologist); 11. Devaux 2019;12. Ottaiano 2019;13. Auvray 2019;14. Chong 2016;15. Yusof 2016. * Combination of diarrhea, stomatitis and abdominal pain (data

not reported separately for each AE).
Key: Adverse events
$10-15 \%$
$>15-20 \%$
$>20-25 \%$
$>25-30 \%$
$>30-35 \%$
$>35-40 \%$
Grade $\geq 3$

Figure 4. Summary of Grade $\geq 3$ adverse events occurring in $\geq 10 \%$ of patients across real-world or retrospective studies of aflibercept in patients with mCRC 
Several retrospective and real-world studies have been performed to analyze Spanish patients (Figure 4). In one study, 167 patients were observed across seven hospitals. The main grade 3 toxicities associated with aflibercept plus FOLFIRI were neutropenia (16.2\%), fatigue (6\%) and diarrhea (5.4\%). Grade $\geq 3$ hypertension and thromboembolic events were observed in $7.2 \%$ and $6 \%$ of patients, respectively [28]. In another Spanish study, which evaluated 66 patients with mCRC who received aflibercept plus FOLFIRI, the most frequent grade $3 / 4$ toxicities were asthenia (13\%), neutropenia $(11.5 \%)$, hypertension $(10 \%)$, diarrhea $(8 \%)$, stomatitis $(3.2 \%)$, palmar-plantar erythrodysesthesia $(3.2 \%)$ and proteinuria (5\%) [29]. In another study evaluating 78 patients who received second-line aflibercept plus FOLFIRI, the most frequently occurring grade $3 / 4$ toxicities were neutropenia (15.3\%), asthenia $(10.3 \%)$, diarrhea $(6.4 \%)$ and mucositis (6.4\%) [30]. Neutropenia (7.9\%) was also the most frequently occurring grade $\geq 3$ toxicity reported in a retrospective analysis of a Spanish Named Patient Program (NPP), which evaluated patients with $\mathrm{mCRC}$ receiving second-line aflibercept plus FOLFIRI. Other frequently reported grade $\geq 3$ toxicities included gastrointestinal disorders (5.6\%; mainly diarrhea, $4.5 \%$ ) and vascular disorders (5.6\%; mainly hypertension, 3.4\%). Most Grade $\geq 3$ AEs were reported during the initial treatment cycles. There were two treatment-related deaths that were due to intestinal perforation [31]. In another retrospective review of a Spanish NPP registry, where 71 patients with mCRC receiving aflibercept plus FOLFIRI were assessed, the most frequently reported grade 3 toxicities were hypertension $(11.3 \%)$, neutropenia (9.9\%), asthenia (8.5\%) and diarrhea (8.5\%) [32]. A retrospective observational study evaluated 71 elderly patients ( $>70$ years) with mCRC across seven hospitals from the Galician Research Group on Digestive Tumours. The most frequently occurring grade 3/4 AEs were asthenia $(18.3 \%)$, neutropenia $(15.5 \%)$, diarrhea $(11.3 \%)$ and mucositis $(9.9 \%)$. The most frequent grade $3 / 4$ related toxicities associated with aflibercept were hypertension (5.6\%), dysphonia $(5.6 \%)$, proteinuria (2.8\%). Two patients experienced grade 5 toxicity [33]. A real-world analysis of 250 Spanish patients with mCRC treated with aflibercept and irinotecan-based chemotherapy has been conducted. The most common grade $3 / 4$ toxicities were neutropenia (13.4\%), hypertension (6.8\%), asthenia (6.8\%), diarrhea (5.4\%) and venous thrombotic disease $(4.2 \%)$. Treatment-related mortality was $1.6 \%$ [34]. A real-world observational study evaluating 120 patients with RAS-WT mCRC who received second-line aflibercept plus FOLFIRI reported hypertension (7.5\%), asthenia (5.9\%) and perforation (2.5\%) as the most frequently occurring [35].

In a French study evaluating FOLFIRI3-aflibercept in 65 evaluable patients with previously treated mCRC, the most frequently reported grade 3/4 AEs were diarrhea (30.8\%), neutropenia (7.7\%), hypertension (3.2\%) and stomatitis (9.2\%) (Figure 4) [36]. One monocentric retrospective study evaluated the FOLFIRI3 regimen given alone $(n=18)$ or in combination with bevacizumab $(n=99)$ or aflibercept $(n=36)$ in French patients with previously treated mCRC. The most frequent grade $3 / 4$ AEs in the aflibercept plus FOLFIRI3 were diarrhea (33\%) and neutropenia (14\%) [37]. The AGEO study evaluated aflibercept plus chemotherapy beyond second-line therapy in patients with mCRC. The most frequent grade 3/4 AEs were asthenia (14.6\%) and diarrhea (8.5\%) [38].

An Italian study of 781 patients who received aflibercept plus FOLFIRI in the real-world setting reported a higher rate of AEs versus other studies (Figure 4). Hypertension (28.5\%), neutropenia (27.5\%; from laboratory data), asthenic conditions $(20.0 \%)$, diarrhea $(17.0 \%)$, and stomatitis $(13.0 \%)$ were the most frequent grade $3 / 4$ toxicities. One toxic death occurred during the study period due to sepsis, without neutropenic complications. There was no significant worsening of HRQL during treatment [39]. In a smaller Italian study of 74 patients with mCRC treated with either second-line FOLFIRI/bevacizumab (Arm A; $n=31$ ) or FOLFIRI/aflibercept (Arm B; $n=43$ ), the most frequently occurring grade 3 toxicity was neutropenia (16.3\% in Arm B). Grade 3 cardiovascular events occurred in $7.0 \%$ of patients in Arm B. No grade 4 events were observed [40].

QoLiTrap was a multinational non-interventional study evaluating the quality of life of 1500 German patients with mCRC previously treated with FOLFIRI plus aflibercept (Figure 4). The most frequent AEs were diarrhea, oral mucositis, fatigue, nausea, and hypertension, predominantly grade $\leq 2[41]$ 
In a US study of aflibercept-containing therapy as a second-line or later-line treatment for $\mathrm{mCRC}$ $(\mathrm{N}=218)$, the most frequent grade $\geq 3$ AEs were gastrointestinal disorders $(11.0 \%)$, asthenia/fatigue (8.7\%), neutropenia (8.7\%) and hypertension (6.4\%) (Figure 4) [42].

\subsubsection{Asian studies}

In a retrospective analysis of 19 patients with $\mathrm{mCRC}$ ( $84 \%$ of Chinese ethnicity) who received second-line aflibercept plus FOLFIRI via a NPP, the most frequently reported grade 3 toxicities were neutropenia (15.8\%), neutropenic complications (15.8\%), diarrhea (10.5\%), bowel obstruction (10.5\%), anemia (10.5\%) and liver enzyme elevation (10.5\%). There were no grade 4 AEs or treatment-related deaths, and all AEs resolved with supportive care management [43] (Figure 4).

Yusof and colleagues conducted a retrospective analysis of Malaysian patients $(\mathrm{N}=25)$ receiving first-line $(n=3)$ or second-line $(n=22)$ aflibercept plus FOLFIRI via a NPP. The most frequently occurring grade $3 / 4$ AEs were weight loss/anorexia (20\%), neutropenia $(16 \%)$, infection $(12 \%)$, hypertension $(8 \%)$ and febrile neutropenia ( $8 \%$ ). AEs were generally reversible and manageable and consistent with those observed in Western populations [44] (Figure 4).

A retrospective study conducted in Taiwan evaluated aflibercept monotherapy in patients with mCRC $(\mathrm{N}=15)$ who had refractory ascites failing to respond to standard chemotherapy. No drug-related AEs were reported; however only a small number of patients were evaluated [45].

Two studies assessing aflibercept plus FOLFIRI in 62 patients and 16 patients with mCRC, respectively, have reported a higher incidence of hematologic AEs compared with other larger studies $[25,26]$.

Overall, safety profiles reported in registry and real-world studies were consistent with those reported in clinical trials. However, rates of grade $\geq 3$ AEs occurred were lower compared with those observed in clinical trials.

\section{Management of aflibercept-Associated Adverse Events in mCRC}

AEs frequently associated with aflibercept therapy for CRC, irrespective of severity, include neutropenia, leukopenia, proteinuria, hypertension, diarrhea, stomatitis, fatigue, decreased weight, decreased appetite, elevated liver enzymes, abdominal pain, dysphonia, increased serum creatinine and headache. Severe AEs have included serious or fatal risk of bleeding, gastrointestinal perforation, and delayed wound healing, though some are related to chemotherapy (generally FOLFORI) [46-48].

The precise mechanisms responsible for the toxicities of aflibercept are not yet fully elucidated. However, hypertension may be influenced by VEGF interaction with the angiotensin system, and proteinuria may be related to VEGF effects on the renal glomerulus $[47,48]$. Thrombosis and hemorrhage could be related to the role of VEGF in vascular integrity [48]. Recommendations for managing the most clinically-relevant AEs associated with aflibercept therapy have been published and focus on hypertension, proteinuria, gastrointestinal perforation, thromboembolism and hemorrhage [48]. These are summarized in Table 3. 
Table 3. General guidelines for aflibercept dosing and schedule modification due to adverse events as categorized by CTCAE 4.0 * [48].

\begin{tabular}{|c|c|}
\hline Event & Action to Be Taken \\
\hline $\begin{array}{l}\text { Hypertension } \\
\text { Grade } 3 \\
\text { Grade } 4\end{array}$ & $\begin{array}{l}\text { If not controlled with medication, discontinue aflibercept } \\
\text { Discontinue aflibercept }\end{array}$ \\
\hline $\begin{array}{l}\text { Proteinuria } \\
>2 \text { g protein/ } 24 \mathrm{~h} \\
\text { Grade } 4 \text { proteinuria (nephrotic syndrome) }\end{array}$ & $\begin{array}{l}\text { Hold aflibercept until proteinuria improves to }<2 \mathrm{~g} \text { of protein } / 24 \mathrm{~h} \\
\text { Discontinue aflibercept in patients with }>2 \mathrm{~g} \text { proteinuria/ } 24 \mathrm{~h} \text { that does not resolve within } 3 \text { months after holding } \\
\text { aflibercept. Work-up for proteinuria such as renal biopsy should be considered } \\
\text { Discontinue aflibercept }\end{array}$ \\
\hline $\begin{array}{l}\text { Gastrointestinal perforation } \\
\text { Gastrointestinal perforation or dehiscence }\end{array}$ & Discontinue aflibercept \\
\hline $\begin{array}{l}\text { Thromboembolic events } \\
\text { Grade } 3 \text { venous thromboembolic event or incidentally } \\
\text { discovered pulmonary embolus first occurrence } \\
\text { Any grade arterial thromboembolic event or symptomatic } \\
\text { Grade } 4 \text { venous thromboembolic event first occurrence }\end{array}$ & $\begin{array}{l}\text { Hold aflibercept treatment } \\
\text { If the planned duration of therapeutic-dose anticoagulant therapy is }<2 \text { weeks, aflibercept should be held until } \\
\text { the period of therapeutic-dose anticoagulant therapy is over } \\
\text { If the planned duration of therapeutic-dose anticoagulant therapy is }>2 \text { weeks, aflibercept should be held for } \\
2 \text { weeks and then may be resumed during the period of therapeutic-dose anticoagulant therapy as soon as all of } \\
\text { the following criteria are met: } \\
\text { - The patient must be on a stable dose of anticoagulant and, if on warfarin, have an INR within the target } \\
\text { range (usually between } 2 \text { and } 3 \text { ) prior to restarting study drug treatment } \\
\text { - The patient has no history of Grade } 3 \text { or } 4 \text { hemorrhagic events before starting aflibercept } \\
\text { The patient has no evidence of tumor invading or abutting major blood vessels on any prior CT scan } \\
\text { Discontinue aflibercept }\end{array}$ \\
\hline $\begin{array}{l}\text { Hemorrhage } \\
\text { Grade } 1 \text { and } 2 \\
\text { Grade } 3 \text { or } 4 \text { (first occurrence) }\end{array}$ & $\begin{array}{l}\text { No dose modification } \\
\text { Discontinue aflibercept }\end{array}$ \\
\hline
\end{tabular}

Grade 3 or 4 (first occurrence)

* CTCAE updated to version 5 ; changes between version 4 and 5 include 
Management of hypertension and proteinuria

Across trials, real-world and retrospective studies, grade $\geq 3$ hypertension and proteinuria are among the most frequently reported AEs. Aflibercept prescribing information contains guidance for timely identification and management of hypertension. Patients receiving aflibercept should have their blood pressure monitored at least every 2 weeks or more regularly as clinically indicated throughout treatment and hypertension should be actively controlled with appropriate therapy. Aflibercept should be withheld in patients whose hypertension is not adequately controlled and only resumed at a reduced dose ( $2 \mathrm{mg} / \mathrm{kg}$ ) for subsequent cycles once hypertension is controlled. Aflibercept should be permanently discontinued for development of hypertensive crisis or hypertensive encephalopathy (Aflibercept PI, 2016). Note that there is no clinical trial experience with aflibercept in patients with New York Heart Association (NYHA) class III/IV heart failure, as it was an exclusion criterion.

There is also specific guidance for management of proteinuria and patients should be monitored by urine dipstick analysis and/or urinary protein creatinine ratio (UPCR) during aflibercept therapy. In case of dipstick $\geq 2+$ or UPCR $>1,24$-h urine collection is mandated. Aflibercept should be withheld for proteinuria $\geq 2 \mathrm{~g} / 24 \mathrm{~h}$ and only resumed when resolved to $<2 \mathrm{~g} / 24 \mathrm{~h}$ Aflibercept should be suspended for recurrent proteinuria and resumed at a reduced dose $(2 \mathrm{mg} / \mathrm{kg})$ on resolution. Aflibercept should be permanently discontinued for development of nephrotic syndrome or thrombotic microangiopathy [48].

\section{Management of Aflibercept-Related Adverse Events in My mCRC Patients- A European Perspective}

The European Society for Medical Oncology (ESMO) guidelines provide clinical recommendations for the management of $\mathrm{mCRC}$ and are implemented routinely in European clinical practice, though not for the management of treatment-related AEs [49].

In my experience, the most frequently occurring AEs in patients who receive aflibercept are hypertension and proteinuria. Management of hypertension is achieved through anti-hypertensive medication, effective patient education and active monitoring throughout treatment. If blood pressure is not controlled by anti-hypertensive medication, temporary discontinuation of aflibercept is considered. Importantly, patients with a persistent blood pressure of $\geq 150 / 90$ are instructed to contact the emergency room for immediate treatment. Proteinuria is effectively managed by regular monitoring by dipstick test throughout treatment and temporary treatment discontinuation.

The frequency and intensity of AEs related to chemotherapy (FOLFIRI) can be potentiated by aflibercept e.g. mucositis and diarrhea. These are often managed by FOLFIRI dose reductions or a temporary discontinuation in aflibercept treatment.

\section{Management of Aflibercept-Related Adverse Events in My mCRC Patients- An Asian Perspective}

The ESMO guidelines have been adapted into pan-Asian consensus guidelines to take into account ethnic differences in toxicity and efficacy of certain systemic treatments in patients of Asian ethnicity [50]. Both guidelines are generally aligned with only a few revisions added in the pan-Asian adaptation. Japanese Society for Cancer of the Colon and Rectum (JSCCR) guidelines for the treatment of CRC [5] have been recently updated and now include aflibercept as one of the options in the category of VEGF-targeted agents [51]. However, as with the ESMO guidelines, there is no focus on management of AEs.

In my experience, the most common AEs observed with aflibercept plus FOLFIRI are consistent with those reported in clinical trials: neutropenia, leukopenia, hypertension, diarrhea, fatigue and decreased appetite. If AEs occur due to this combination treatment, the causative agent should be identified, if possible. These toxicities can be managed using symptomatic treatment for prevention, and in the majority of cases of AEs, aflibercept treatment is continued. In rare cases, treatment may need to be changed or discontinued but, according to UPCR guidelines, this is only with the 
occurrence of serious (grade $\geq 3$ ) proteinuria with inadequate treatment response, according to UPCR guidelines. Dose reductions of 5 -fluorouracil should be considered in cases of grade $\geq 3$ neutropenia, grade $\geq 3$ fatigue and diarrhea. Reduction of aflibercept should be considered in cases of for grade $\geq$ 3 proteinuria.

Rarely, granulocyte-colony stimulating factor (G-CSF) is used for prophylactic and therapeutic treatment of neutropenia. Low-risk patients without fever will not receive G-CSF even if they have grade 4 neutropenia when using FOLFIRI with aflibercept. However, the use of G-CSF varies across intuitions. Antimicrobial agents should be administered in cases of febrile neutropenia.

In the management of hypertension, patients are started with a calcium antagonist; there is a paucity of evidence for effective front-line treatment with angiotensin-receptor blockers (ARBs) in this setting. Calcium channel antagonists are also considered to be effective because of their relatively strong antihypertensive effect and the mechanism of action that reduces vascular smooth muscle cell contraction caused by impaired NO signaling induced by VEGF inhibitors. We consider the use of ARBs, angiotensin-converting-enzyme (ACE) inhibitors, beta-blockers and diuretics, dependent on the patient's condition, but most frequently use a combination of calcium antagonist plus ARB or ACE inhibitor. Hypertension could generally be improved by stopping or reducing the dose of VEGF inhibitors, since hypertension with the causative drug is reversible.

In cases of diarrhea, symptomatic treatment may be incorporated using loperamide or infusion treatment (for the worst cases of dehydration only). Prophylactic treatment with 5-hydroxytryptamine type 3 and steroids are used for the prevention of vomiting. Thus, we find that the safety profile of aflibercept is manageable; most AEs can be controlled without the need to discontinue treatment.

\section{Discussion}

Our review of the AEs reported among patients with $\mathrm{mCRC}$ receiving aflibercept in different populations and settings indicates that the range, incidence and severity of aflibercept-associated AEs is generally evenly distributed across geographies and in some instances appear to be less frequently reported in real-world/retrospective studies compared with clinical trials.

In the US real-world study by Ivanova and colleagues, although patients receiving aflibercept were more heavily pretreated and potentially less robust compared with the VELOUR trial, AE rates were similar to or lower than the VELOUR trial [42]. However, the lower incidence of reported AEs in the post-marketing setting may be due to underreporting as the reliance is on spontaneous reporting, which may fail to capture all occurring AEs [52].

Guidance for the management of clinically relevant AEs is available [48]. Of note, strict monitoring of blood pressure and immediate management of hypertension during therapy is mandatory [19]. In the large randomized trial of aflibercept plus FOLFIRI versus placebo plus FOLFIRI, although grade 3/4 AEs were more frequent in the aflibercept arm, they occurred in early treatment cycles and decreased sharply following initial presentation [14].

\section{Conclusions}

Aflibercept is an antiangiogenic agent that targets VEGF-A, VEGF-B and PIGF. It was approved for the treatment of patients with $\mathrm{mCRC}$ who had progressed on oxaliplatin following the pivotal VELOUR trial.

Data suggests that the AE profile of aflibercept combination therapy trends towards being more favorable in the real-world compared with clinical trial settings, with no new safety signals identified irrespective of geographical location. Real-world studies reported neutropenia, hypertension and gastrointestinal AEs as being frequently associated with aflibercept, similar to clinical trials. However, the rates at which these occurred was often lower in real-world studies compared with clinical trials. This may be a result of under-reporting or improved patient management. Furthermore, AEs are generally manageable and comparable across various geographic locations. As such, safety experience 
gained in clinical trials can translate into the clinical setting across various countries, for example, identifying when extra vigilance and close monitoring may be appropriate.

Author Contributions: All authors have read and agree to the published version of the manuscript. Conceptualization, K.M., T.M., T.S. and A.R.S.; methodology, K.M. and T.M..; investigation, K.M., T.M., T.S. and A.R.S.; writing — original draft preparation, K.M., T.M., T.S. and A.R.S.; writing—review and editing, K.M., T.M., T.S. and A.R.S.

Funding: This research was funded by Sanofi.

Acknowledgments: Research and analysis were supported by Sanofi. The authors were responsible for all content and editorial decisions and received no honoraria for development of this manuscript. Medical writing assistance was provided by Amber Wood of Meditech Media, funded by Sanofi.

Conflicts of Interest: K.M. reports grants from MSD, grants from Daiichi Sankyo, Parexel International, Sumitomo Dainippon Pharma, Pfizer, Mediscience Planning, Solasia Pharma, Merck Serono and Sanofi. Personal fees were received from Sanofi, Eli Lilly, Chugai Pharmaceutical, Takeda Pharmaceutical, Taiho Pharmaceutical, Bristol-Myers Squibb, Bayer and ONO Pharmaceutical. TM reports grants from Agios, Aslan, AstraZeneca, Bayer, Celgene, Genentech, Hallozyme, Immunomedics, Lilly, Merimarack, Millennium, Novartis, Novocure, Pfizer, Pharmacyclics and Roche. Personal fees were received from Baxalta, Bayer, Celgene, Genzyme, H3B, QED, Merck, Roche, Sanofi and Shire, T.S. and A.R.S. are employees of Sanofi.

\section{References}

1. Arnold, M.; Sierra, M.S.; Laversanne, M.; Soerjomataram, I.; Jemal, A.; Bray, F. Global patterns and trends in colorectal cancer incidence and mortality. Gut 2017, 66, 683-691. [CrossRef]

2. Bray, F.; Ferlay, J.; Soerjomataram, I.; Siegel, R.L.; Torre, L.A.; Jemal, A. Global cancer statistics 2018: GLOBOCAN estimates of incidence and mortality worldwide for 36 cancers in 185 countries. CA Cancer J. Clin. 2018, 68, 394-424. [CrossRef] [PubMed]

3. Ferlay, J.; Colombet, M.; Soerjomataram, I.; Dyba, T.; Randi, G.; Bettio, M.; Gavin, A.; Visser, O.; Bray, F. Cancer incidence and mortality patterns in Europe: Estimates for 40 countries and 25 major cancers in 2018. Eur. J. Cancer 2018, 103, 356-387. [CrossRef] [PubMed]

4. Pourhoseingholi, M.A. Increased burden of colorectal cancer in Asia. World J. Gastrointest. Oncol. 2012, 4, 68-70. [CrossRef] [PubMed]

5. Watanabe, T.; Muro, K.; Ajioka, Y.; Hashiguchi, Y.; Ito, Y.; Saito, Y.; Hamaguchi, T.; Ishida, H.; Ishiguro, M.; Ishihara, S. Japanese Society for Cancer of the Colon and Rectum (JSCCR) guidelines 2016 for the treatment of colorectal cancer. Int. J. Clin. Oncol. 2018, 23, 1-34. [CrossRef] [PubMed]

6. Sung, J.J.Y.; Chiu, H.M.; Jung, K.W.; Jun, J.K.; Sekiguchi, M.; Matsuda, T.; Kyaw, M.H. Increasing trend in young-onset colorectal cancer in Asia: More cancers in men and more rectal cancers. Am. J. Gastroenterol. 2019, 114, 322-329. [CrossRef]

7. Van Cutsem, E.; Joulain, F.; Hoff, P.M.; Mitchell, E.; Ruff, P.; Lakomý, R.; Prausová, J.; Moiseyenko, V.M.; van Hazel, G.; Cunningham, D.; et al. Aflibercept plus FOLFIRI vs. PLACEBO PLUS FOLFIRI in second-line metastatic colorectal cancer: A post hoc analysis of survival from the phase III VELOUR study subsequent to exclusion of patients who had recurrence during or within 6 months of completing adjuvant oxaliplatin-based therapy. Target. Oncol. 2016, 11, 383-400.

8. Clarke, J.M.; Hurwitz, H.I.; Rangwala, F. Understanding the mechanisms of action of antiangiogenic agents in metastatic colorectal cancer: A clinician's perspective. Cancer Treat. Rev. 2014, 40, 1065-1072. [CrossRef]

9. Hayman, S.R.; Leung, N.; Grande, J.P.; Garovic, V.D. VEGF inhibition, hypertension, and renal toxicity. Curr. Oncol. Rep. 2012, 14, 285-294. [CrossRef]

10. Rajabi, M.; Mousa, S.A. The role of angiogenesis in cancer treatment. Biomedicines 2017, 5, 34. [CrossRef]

11. Van Cutsem, E.; Tabernero, J.; Lakomy, R.; Prenen, H.; Prausová, J.; Macarulla, T.; Ruff, P.; van Hazel, G.A.; Moiseyenko, V.; Ferry, D.; et al. Addition of aflibercept to fluorouracil, leucovorin, and irinotecan improves survival in a phase III randomized trial in patients with metastatic colorectal cancer previously treated with an oxaliplatin-based regimen. J. Clin. Oncol. 2012, 30, 3499-3506. [CrossRef] [PubMed]

12. Ruff, P.; Van Cutsem, E.; Lakomy, R.; Prausova, J.; van Hazel, G.A.; Moiseyenko, V.M.; Soussan-Lazard, K.; Dochy, E.; Magherini, E.; Macarulla, T.; et al. Observed benefit and safety of aflibercept in elderly patients with metastatic colorectal cancer: An age-based analysis from the randomized placebo-controlled phase III VELOUR trial. J. Geriatr. Oncol. 2018, 9, 32-39. [CrossRef] [PubMed] 
13. Chau., I.; Joulain., F.; Iqbal, S.U.; Bridgewater, J. A VELOUR post hoc subset analysis: Prognostic groups and treatment outcomes in patients with metastatic colorectal cancer treated with aflibercept and FOLFIRI. BMC Cancer 2014, 14, 605. [CrossRef] [PubMed]

14. Ruff, P.; Ferry, D.R.; Lakomỳ, R.; Prausová, J.; Van Hazel, G.A.; Hoff, P.M.; Cunningham, D.; Arnold, D.; Schmoll, H.J.; Moiseyenko, V.M.; et al. Time course of safety and efficacy of aflibercept in combination with FOLFIRI in patients with metastatic colorectal cancer who progressed on previous oxaliplatin-based therapy. Eur. J. Cancer 2015, 51, 18-26. [CrossRef] [PubMed]

15. Riechelmann, R.P.; Srimuninnimit, V.; Bordonaro, R.; Kavan, P.; Di Bartolomeo, M.; Maiello, E.; Cicin, I.; García-Alfonso, P.; Chau, I.; Fedyanin, M.Y.; et al. Aflibercept plus FOLFIRI for second-line treatment of metastatic colorectal cancer: Observations from the global Aflibercept Safety and Health-Related Quality-of-Life Program (ASQoP). Clin. Colorectal Cancer 2019, 18, 183-191. [CrossRef]

16. Riechelmann, R.; Srimuninnimit, V.; Kavan, P.; Di Bartolomeo, M.; Maiello, E.; Cicin, I.; Kröning, H.; Garcia-Alfonso, P.; Chau, I.; Fernández-Martos, C.; et al. Aflibercept plus FOLFIRI for 2nd line treatment of metastatic colorectal cancer (mCRC): Long-term safety observation from the glo;al aflibercept safety and quality-of-life (QoL) program (ASQoP). Ann. Oncol. 2016, 27, 552. [CrossRef]

17. Folprecht, G.; Pericay, C.; Saunders, M.P.; Thomas, A.; Lopez Lopez, R.; Roh, J.K.; Chistyakov, V.; Höhler, T.; Kim, J.S.; Hofheinz, R.D.; et al. Oxaliplatin and 5-FU/folinic acid (modified FOLFOX6) with or without aflibercept in first-line treatment of patients with metastatic colorectal cancer: The AFFIRM study. Ann. Oncol. 2016, 27, 1273-1279. [CrossRef]

18. Lambrechts, D.; Thienpont, B.; Thuillier, V.; Sagaert, X.; Moisse, M.; Peuteman, G.; Pericay, C.; Folprecht, G.; Zalcberg, J.; Zilocchi, C.; et al. Evaluation of efficacy and safety markers in a phase II study of metastatic colorectal cancer treated with aflibercept in the first-line setting. Br. J. Cancer 2015, 113, 1027-1034. [CrossRef]

19. Chibaudel, B.; Bachet, J.B.; Andre, T.; Auby, D.; Desrame, J.; Deplanque, G.; Lecaille, C.; Louvet, C.; Tournigand, C.; Lebrun-Ly, V.; et al. Efficacy of aflibercept with FOLFOX and maintenance with fluoropyrimidine as firstline therapy for metastatic colorectal cancer: GERCOR VELVET phase II study. Int. J. Oncol. 2019, 54, 1433-1445.

20. Pentheroudakis, G.; Kotoula, V.; Koliou, G.-A.; Karavasilis, V.; Samantas, E.; Aravantinos, G.; Kalogeropoulou, L.; Souglakos, I.; Kentepozidis, N.; Koumakis, G.; et al. AMALTHEA: Prospective, single-arm study of the Hellenic Cooperative Oncology Group (HeCOG) evaluating efficacy and safety of first-line FOLFIRI+ aflibercept for 6 months followed by aflibercept maintenance in patients with metastatic colorectal cancer. Clin. Colorectal Cancer 2018, 17, e631-e637. [CrossRef]

21. Matikas, A.; Souglakos, J.; Katsaounis, P.; Kotsakis, A.; Kouroupakis, P.; Pantazopoulos, N.; Kentepozidis, N.; Nikolaidi, A.; Messaritakis, I.; Tzovara, I.; et al. MINOAS: A Single-arm Translational Phase II Trial of FOLFIRI Plus Aflibercept as First-line Therapy in Unresectable, Metastatic Colorectal Cancer. Target. Oncol. 2019, 14, 285-293. [CrossRef] [PubMed]

22. Lapeyre-Prost, A.; Pernot, S.; Sigrand, J.; Mary, F.; Le Malicot, K.; Aparicio, T.; Dahan, L.; Caroli-Bosc, F.X.; Lecomte, T.; Racine Doat, S.; et al. Aflibercept in combination with irinotecan, fluorouracil and leucovorin (FOLFIRI) as first-line chemotherapy in metastatic colorectal cancer (mCRC) patients: A phase II multicentric study. Ann. Oncol. 2018, 29, viii160. [CrossRef]

23. Tang, P.A.; Cohen, S.J.; Kollmannsberger, C.; Bjarnason, G.; Virik, K.; MacKenzie, M.J.; Lourenco, L.; Wang, L.; Chen, A.; Moore, M.J. Phase II clinical and pharmacokinetic study of aflibercept in patients with previously treated metastatic colorectal cancer. Clin. Cancer Res. 2012, 18, 6023-6031. [CrossRef] [PubMed]

24. Li, J.; Xu, R.; Qin, S.; Liu, T.; Pan, H.; Xu, J.; Bi, F.; Lim, R.; Zhang, S.; Ba, Y.; et al. Aflibercept plus FOLFIRI in Asian patients with pretreated metastatic colorectal cancer: A randomized Phase III study. Future Oncol. 2018, 14, 2031-2044. [CrossRef] [PubMed]

25. Denda, T.; Sakai, D.; Hamaguchi, T.; Sugimoto, N.; Ura, T.; Yamazaki, K.; Fujii, H.; Kajiwara, T.; Nakajima, T.E.; Takahashi, S.; et al. Phase II trial of aflibercept with FOLFIRI as a second-line treatment for Japanese patients with metastatic colorectal cancer. Cancer Sci. 2019, 110, 1032-1043. [CrossRef]

26. Yoshino, T.; Yamazaki, K.; Yamaguchi, K.; Doi, T.; Boku, N.; Machida, N.; Onozawa, Y.; Asayama, M.; Fujino, T.; Ohtsu, A. A phase I study of intravenous aflibercept with FOLFIRI in Japanese patients with previously treated metastatic colorectal cancer. Investig. New Drugs 2013, 31, 910-917. [CrossRef] [PubMed] 
27. Xu, J.; Li, Y.; Sun, X.; Zhang, D.; Liu, R.; Ziti-Ljajic, S.; Shi, D.; Xue, F.; Le bail, N.; Xu, R. A phase I and pharmacokinetic study of afilbercept with FOLFIRI: Comparison of Chinese and Caucasian populations. Investig. New Drugs 2017, 35, 463-470. [CrossRef] [PubMed]

28. Fernandez Montes, A.; Carlos Lopez, L.; Carmona, A.; Paez, D.; Lopez Munoz Ana, M.; Gutierrez Abad, D.; Carmen Castanon, L.; Maria, D.; Eva Martinez, C.; Manuel Sanchez, C.; et al. Efficacy and toxicity results of FOLFIRI-Aflibercept in advanced colorectal cancer (CRCm) in "real life", retrospective study. Prognostic factors and specific populations. Ann. Oncol 2017, 28, iii103. [CrossRef] [PubMed]

29. Gonzalez-Flores, E.; Gonzalez-Astorga, B.; Delgado Urena Ma, T.; Gonzalez Cebrian, I.; Sanchez-Toro, C.; Garcia-Garcia, J.; Conde, V. Experience with aflibercept as a second line chemotherapy in metastatic colorectal cancer: Safety and efficacy in a real-life population. Ann. Oncol. 2017, 28, iii110-iii111. [CrossRef]

30. Fernández Montes, A.; Martínez Lago, N.; Covela Rúa, M.; de la Cámara Gómez, J.; González Villaroel, P.; Méndez Méndez, J.C.; Jorge Fernández, M.; Salgado Fernández, M.; Reboredo López, M.; Quintero Aldana, G.; et al. Efficacy and safety of FOLFIRI/aflibercept in second-line treatment of metastatic colorectal cancer in a real-world population: Prognostic and predictive markers. Cancer Med. 2019, 8, 882-889. [CrossRef]

31. Salgado Fernández, M.; Pérez Hoyos, M.T.; Díaz de Corcuera, I.; Vidal Arbués, A.; García de la Torre, M. Aflibercept for metastatic colorectal cancer: Safety data from the Spanish named patient program. Expert Opin. Drug Saf. 2015, 14, 1171-1179. [CrossRef] [PubMed]

32. Feliu, J.; Díez de Corcuera, I.; Manzano, J.L.; Valladares-Ayerbes, M.; Alcaide, J.; García García, T.; Vera, R.; Sastre, J. Effectiveness and safety of aflibercept for metastatic colorectal cancer: Retrospective review within an early access program in Spain. Clin. Transl. Oncol. 2017, 19, 498-507. [CrossRef] [PubMed]

33. Martinez-Lago, N.; Carmona Campos, M.; Gonzalez Villarroel, P.; Salgado Fernandez, M.; De la Camara Gomez, J.; Romero Reinoso, C.; Cousillas Castineiras, A.; Mendez Mendez, J.; Vidal Insua, Y.; Reboredo Rendo, C.; et al. Efficacy and safety of FOLFIRI/Aflibercept (FA) in an elderly population with metastatic colorectal cancer (mCRC) after the failure of an oxaliplatin-based regimen. Ann. Oncol. 2019, 30, iv42-iv43. [CrossRef] [PubMed]

34. Fernandez Montes, A.; Lopez Lopez, C.; Argiles Martinez, G.; Paez Lopez, D.; Lopez Munoz, A.M.; Garcia Paredes, B.; Gutierrez Abad, D.; Castanon Lopez, C.; Jimenez Fonseca, P.; Gallego Plazas, J.; et al. Prognostic Nomogram and Patterns of Use of FOLFIRI-Aflibercept in Advanced Colorectal Cancer: A Real-World Data Analysis. Oncologist 2019, 24, e687-e695. [CrossRef]

35. Vera, R.; Mata, E.; Gonzalez, E.; Juez, I.; Alonso, V.; Iranzo, P.; Martinez, N.P.; Lopez, C.; Cabrera, J.M.; Safont, M.J.; et al. Is aflibercept an optimal treatment for wt RAS mCRC patients after progression to first line containing anti-EGFR? Int J. Colorectal Dis. 2020, 35, 739-746. [CrossRef] [PubMed]

36. Carola, C.; Ghiringhelli, F.; Kim, S.; André, T.; Barlet, J.; Bengrine-Lefevre, L.; Marijon, H.; Garcia-Larnicol, M.-L.; Borg, C.; Dainese, L.; et al. FOLFIRI3-aflibercept in previously treated patients with metastatic colorectal cancer. World J. Clin. Oncol. 2018, 9, 110-118. [CrossRef]

37. Devaux, M.; Gerard, L.; Richard, C.; Bengrine-Lefevre, L.; Vincent, J.; Schmitt, A.; Ghiringhelli, F. Retrospective evaluation of FOLFIRI3 alone or in combination with bevacizumab or aflibercept in metastatic colorectal cancer. World J. Clin. Oncol. 2019, 10, 75-85. [CrossRef]

38. Auvray, M.; Tougeron, D.; Auclin, E.; Moulin, V.; Artru, P.; Hautefeuille, V.; Hammel, P.; Lecomte, T.; Locher, C.; Sickersen, G.; et al. Efficacy and Safety of Aflibercept in Combination With Chemotherapy Beyond Second-Line Therapy in Metastatic Colorectal Carcinoma Patients: An AGEO Multicenter Study. Clin. Colorectal Cancer 2020, 19, 39-47.e5. [CrossRef]

39. Pastorino, A.; Di Bartolomeo, M.; Maiello, E.; Iaffaioli, V.; Ciuffreda, L.; Fasola, G.; Di Costanzo, F.; Frassineti, G.L.; Marchetti, P.; Antoniotti, C.; et al. Aflibercept plus FOLFIRI in the real-life setting: Safety and quality of life data from the Italian patient cohort of the Aflibercept Aafety and Quality-of-Life Program study. Clin. Colorectal Cancer 2018, 17, e457-e470. [CrossRef]

40. Ottaiano, A.; Capozzi, M.; Tafuto, S.; De Stefano, A.; De Divitiis, C.; Romano, C.; Avallone, A.; Nasti, G. Folfiri-Aflibercept vs. Folfiri-Bevacizumab as Second Line Treatment of RAS Mutated Metastatic Colorectal Cancer in Real Practice. Front. Oncol. 2019, 9, 766. [CrossRef]

41. Hofheinz, R.; Scholten, F.; Derigs, H.; Thaler, J.; von Moos, R. Quality of life in patients treated with aflibercept and FOLFIRI for metastatic colorectal cancer: Interim analysis with focus on therapy lines of the non-interventional study QoLiTrap (AIO-LQ-0113). Ann. Oncol. 2019, 30, iv118. [CrossRef] [PubMed] 
42. Ivanova, J.I.; Saverno, K.R.; Sung, J.; Duh, M.S.; Zhao, C.; Cai, S.; Vekeman, F.; Peevyhouse, A.; Dhawan, R.; Fuchs, C.S. Real-world treatment patterns and effectiveness among patients with metastatic colorectal cancer treated with ziv-aflibercept in community oncology practices in the USA. Med. Oncol. 2017, 34, 193. [CrossRef] [PubMed]

43. Chong, D.Q.; Manalo, M.; Imperial, M.; Teo, P.; Yong, G.; Ng, M.; Tan, I.B.H.; Choo, S.P.; Chua, C. Safety and efficacy of aflibercept in combination with fluorouracil, leucovorin and irinotecan in the treatment of Asian patients with metastatic colorectal cancer. Asia-Pac. J. Clin. Oncol. 2016, 12, 275-283. [CrossRef] [PubMed]

44. Yusof, M.M.; Abdullah, N.; Sharial, M.S.N.; Zaatar, A. Safety and management of toxicity related to aflibercept in combination with fluorouracil, leucovorin and irinotecan in Malaysian patients with metastatic colorectal cancer. Asian Pac. J. Cancer Prev. 2016, 17, 973-978. [CrossRef]

45. Lu, C.-S.; Lin, J.-K.; Chen, W.-S.; Lin, T.-C.; Jiang, J.-K.; Yang, S.-H.; Wang, H.-S.; Chang, S.-C.; Lan, Y.-T.; Lin, C.-C.; et al. Intraperitoneal ziv-aflibercept effectively manages refractory ascites in colorectal cancer patients. Oncotarget 2017, 8, 36707-36715. [CrossRef]

46. Geng, F.; Wang, Z.; Yin, H.; Yu, J.; Cao, B. Molecular targeted drugs and treatment of colorectal cancer: Recent progress and future perspectives. Cancer Biother. Radiopharm. 2017, 32, 149-160. [CrossRef]

47. Zhang, B.; Fang, C.; Deng, D.; Xia, L. Research progress on common adverse events caused by targeted therapy for colorectal cancer. Oncol. Lett. 2018, 16, 27-33. [CrossRef]

48. Saif, M.W.; Relias, V.; Syrigos, K.; Gunturu, K.S. Incidence and management of ZIv-aflibercept related toxicities in colorectal cancer. World J. Clin. Oncol 2014, 5, 1028-1035. [CrossRef]

49. Van Cutsem, E.; Cervantes, A.; Adam, R.; Sobrero, A.; Van Krieken, J.H.; Aderka, D.; Aranda Aguilar, E.; Bardelli, A.; Benson, A.; Bodoky, G.; et al. ESMO consensus guidelines for the management of patients with metastatic colorectal cancer. Ann. Oncol. 2016, 27, 1386-1422. [CrossRef]

50. Yoshino, T.; Arnold, D.; Taniguchi, H.; Pentheroudakis, G.; Yamazaki, K.; Xu, R.H.; Kim, T.W.; Ismail, F.; Tan, I.B.; Yeh, K.H.; et al. Pan-Asian adapted ESMO consensus guidelines for the management of patients with metastatic colorectal cancer: A JSMO-ESMO initiative endorsed by CSCO, KACO, MOS, SSO and TOS. Ann. Oncol. 2018, 29, 44-70. [CrossRef]

51. Hashiguchi, Y.; Muro, K.; Saito, Y.; Ito, Y.; Ajioka, Y.; Hamaguchi, T.; Hasegawa, K.; Hotta, K.; Ishida, H.; Ishiguro, M.; et al. Japanese Society for Cancer of the Colon and Rectum (JSCCR) guidelines 2019 for the treatment of colorectal cancer. Int. J. Clin. Oncol. 2020, 25, 1-42. [CrossRef] [PubMed]

52. Ahmad, S.R. Adverse drug event monitoring at the Food and Drug Administration. J. Gen. Intern. Med. 2003, 18, 57-60. [CrossRef] [PubMed]

(C) 2020 by the authors. Licensee MDPI, Basel, Switzerland. This article is an open access article distributed under the terms and conditions of the Creative Commons Attribution (CC BY) license (http://creativecommons.org/licenses/by/4.0/). 